\title{
Communicating with Library Patrons and Dementia Patients: Tracing an Ethic of Care Practice in Professional Communication Guidelines
}

\section{Introduction}

This paper arose from an intuition: that reference librarians have skills that can be productively transferred to dementia care. In 1991, Carol Kulthau articulated the various affective states that accompany different stages of the Information Search Process. The exploration stage, she argued, is characterized by feelings of confusion, frustration, and doubt: "Users may find the situation quite discouraging and threatening, causing a sense of personal inadequacy as well as frustration with the system" (1991, p. 367). In January 2017, an individual with Alzheimer's disease responded to a message on "Alz Connected," the Alzheimer's Association message board, in which she described her tendency to become hostile and aggressive: "My guess would be aggression and hostility are from our cognitive capacity being overwhelmed. ... Most "bad behavior" is misunderstood frustration, pressure from within our own selves or other people pressuring us to perform. I kept trying to keep up and BOOM."

The affective states are too similar to ignore. Clearly, certain stages of the information search process arouse feelings - and responses to those feelings - that resemble the challenges of living with dementia.

If the problems are similar, so are the mediating strategies of professionals who seek to provide help: strategies of detection and intervention that evolve through long experience, trial and error, and pooling of insights and suggestions within a community. According to Harmeyer's anecdotal account of providing reference through online chat, "occasionally, chat librarians need to play the role of crossword puzzle takers, intuitively filling in missing pieces and doing a bit of detective work and outright mindreading" (2016, p. 260). In April 2017, a caregiver on Alz Connected described symptoms of obsessive-compulsive disorder in her mother, and promptly received a range of suggestions, ranging from checking for a possible iron deficiency to distraction techniques.

In both reference work and dementia care, communication is complicated, and interactions can often become frustrating for both parties, sometimes degenerating into hostility. Professionals in both fields, therefore, have developed protocols and standards to assist personnel in handling these interactions. To what extent are these interactions similar? And to what extent does the practice of librarianship offer skills and insights for those working with individuals living with dementia?

\section{Background}

Global population aging has been characterized as "unprecedented, pervasive, profound, and enduring" (United Nations, 2002). The World Health Organization (2015) estimates the number of people aged 60 years or older will rise from 900 million to 2 billion between 2015 
and 2050. As of July 2015, for the first time in Canadian history, the number of older adults over the age of 65 outnumbered the number of children under the age of 15 (Statistics Canada, 2015) and by 2036, the nearly one in four Canadians will be over the age of 65 (Statistics Canada, 2014).

Alzheimer's disease (AD), the most common cause of dementia, is marked by losses and changes in memory, thinking, mood and behaviours, as cognitive abilities progressively deteriorate (Alzheimer Society of Canada, 2010). Alzheimer's disease and other forms of dementia are the most significant cause of disability among Canadians over the age of 65 , affecting nearly 747,000 Canadians, a number expected to double by 2031 (Alzheimer Society of Canada, 2012).

As Canada and other nations grapple with the growing challenge of dementia care, many different disciplines are discovering that their domain-specific training has relevance to this challenge. Information studies is no exception. In addition to providing access to information resources, reviewing resources, and providing innovative programming (Cochrane, Knocker, \& Towers, 2014; Dankowski, 2015; CILIP, 2014), information practitioners and scholars are exploring, more broadly, ways of communicating information to individuals living with dementia as their disease progresses. As individuals living with dementia may "end up prematurely or inappropriately in residential long-term care (LTC)" (Morton-Chang, 2015, p. ii), understanding how to better communicate with those living with dementia is of critical importance to enable their ability to live in the community for as long as they desire. New technologies, including smart homes that provide prompts (Kenner, 2008) and interface and information architecture design (Campbell, 2007), offer compelling and attractive possibilities; particularly those associated with big data and the Internet of Things.

\section{Methods}

This particular study, however, is grounded in an ethic of care approach. Drawing on the feminist work of Gilligan (1982) and Tronto (1993), we argue that the communication of information in dementia settings is best approached through a lens that emphasizes the importance of interpersonal relationships, reciprocity and empathetic benevolence. Within a frame of four ethical elements (attentiveness, responsibility, competence and responsiveness) (Tronto, 1993), an ethic of care is a way of thinking about the world that argues for the deprivatization and de-gendering of care (Sevenhuijsen, 2003) and calls for the recognition of care as a human need. From this perspective, information studies has a rich heritage and tradition of providing empathetic and helpful communication in complex and cognitively demanding situations. As information scholars have long observed and studied, information professionals confront a range of emotional responses to the information search process (Kuhlthau, 1988, 1993; Mellon, 1986), many of which - responses of despondency, anxiety, confusion and avoidance, if not outright hostility - resemble responses encountered by workers in dementia care. This exploratory study charts some of the similarities and differences in communicative acts in library studies and dementia studies, as articulated in a set of widely-used guidelines for each domain.

\section{Overview of Guidelines}

The American Library Association's Reference and User Services Association's (RUSA) Guidelines for Behavioral Performance of Reference and Information Service Providers, first published in 1996, were created to "identify and recommend observable behavioral attributes that could be correlated with positive patron perceptions of reference librarian performance". RUSA (2008) defines reference work as "reference transactions and other activities that 
involve the creation, management, and assessment of information or research resources, tools, and services." These Guidelines, revised in 2004 and 2011, include five key areas: visibility/approachability, interest, listening/inquiring, searching and follow up.

NICE, the National Institute for Health and Care Excellence, provides guidance and advice to improve health outcomes and social care in the United Kingdom. Developed by a multidisciplinary team of health and social care professionals, a person with dementia, and caregivers, the Social Care Institute for Excellence and the National Institute for Health and Clinical Excellence published a Guideline on Supporting People with Dementia and their Carers in Health and Social Care in 2006. This detailed Guideline, at 392 pages, is for "health and social care staff who work with people with dementia and their carers, and those who work with older people and people with learning disabilities" (2006).

\section{Findings}

As we sought to understand what communicative interactions 'look like' in each of these guidelines, by following the threads of information (Bates, 1999) woven within each of these Guidelines, we uncovered a significant overlap between the communicative practices of librarians and health care professionals. From our readings of the two guideline documents, five themes common to both documents emerged: the need for vigilance, management of risk, the need for respect, maintenance and promotion of individuals' independence, and the notion that this is a shared experience between patients or patrons and professionals (whether librarians or health care professionals). While from different domains, both sets of Guidelines establish a rubric of procedures for dealing with interactions that could, in both cases, be complex and frightening, both for the service provider (librarian or dementia care worker) and the service recipient (library patron or individual living with dementia). We also discovered, in both sets of Guidelines, an underlying ethic of care as an activity; as something that entails an act of attentiveness, benevolence, respect, and non-judgment. For example, the NICE Guideline 1.1.1.1 advises that "People with dementia should not be excluded from any services because of their diagnosis, age (whether designated too young or too old) or coexisting learning disabilities." Similarly, RUSA's Guideline 3.1.9 offers the following recommendation for information professionals: "Maintains objectivity; does not interject value judgments about the subject matter or the nature of the question into the transaction." The similarities between the two sets of Guidelines suggest that librarianship and dementia care share an obligation to take up the four ethical elements and perform necessary and important communicative tasks, with sympathy, tact and respect, emphasizing and recognizing the rights and the feelings of the service recipient.

Despite these similarities, the Guidelines for reference service and for dementia care contain some intriguing differences, perhaps indicative that the four ethical elements resonate to different degrees within each of the Guidelines and their respective disciplines. The general RUSA Guidelines place great emphasis on being approachable, displaying interest, using good listening and inquiring skills, and following up the reference interview, coupled with understandable need for adept searching skills. The NICE Guidelines, on the other hand, place primary emphasis on clinically-based procedures for diagnosing specific conditions, allowing for diversity of needs (such as diet, religion and sexuality), obtaining valid consent, responding to non-cognitive symptoms, and ensuring equitable access to services (NICE, 2006), coupled with the understandable need to treat all residents with respect at all times.

In addition, the RUSA Guidelines frame "care" specifically as empathy: attention, listening and approachability, all tempered with an affective awareness. While RUSA's more specific 
guidelines on reference service for health and medical reference service place a greater emphasis on the importance of accessing reliable and authoritative information, in both sets of guidelines, the process of caring is largely one of communicating non-judgmental, nonthreatening, tactful openness; intended to establish, on the part of the service recipient, trust and a willingness to share needs openly. The NICE Guidelines frame "care" in a more multifaceted fashion. The quality of respect goes beyond the immediate interaction. It involves ensuring that the individual's rights are formally respected; it involves diagnosing the individual's condition accurately, promptly and fully; it involves ensuring that appropriate consent has been obtained for all procedures; it involves ensuring that care workers are properly trained for their tasks; it ensures that multiple health services for an individual are accurately and appropriately coordinated (NICE, 2006). In the NICE Guidelines, "care" is a less affective, more abstract concept, in which care manifests itself through sets of procedures that ensure, regardless of the emotional tone of individual interactions, the needs of the individual with dementia remain paramount, and are not submerged in the inevitable complexities and logistics of administering long-term care.

\section{Discussion}

Beneath both sets of Guidelines, we detected a powerful motivation to protect the person delivering the service, be it in reference service or dementia care. The RUSA Guidelines aim, at least in part, to protect information professionals, both from the stress of undue demands (Westbrook, 2015) and possible culpability in the event of the user receiving inaccurate information. Implicit, therefore, in the RUSA Guidelines is the importance of good emotional affect, regardless of the success or failure of the specific task. The NICE Guidelines, for their part, aim to protect the care worker from the stress of inevitable challenging interactions in a dementia care setting. No long-term care facility is able to spare its resident from the aging process (which may include loneliness, disorientation, etc.) nor is any long-term care facility entirely free of interactions that involve fear or hostility. In both domains, the Guidelines therefore delicately balance two roles: in addition to ensuring respect for the patron or dementia patient, they also provide the protection of codified, documented care procedures.

In both cases, the Guidelines frame the act of communication between the service provider and the service recipient as a complex one which demands an ethic of care that acknowledges the profound moral responsibility to protect both parties from the consequences of transactions that may manifest as confusion, misunderstanding and potential hostility. Tracing the communicative interactions within the RUSA and NICE Guidelines using an ethic of care lens kept and held care as central to our analysis and may be a rich analytical tool for both library and health communities to elucidate "communication accidents" (Dewdney \& Michell, 1996). This relatively novel approach (particularly within LIS) enabled us to begin to uncover intriguing commonalities and differences in communicative interactions in professional communication guidelines in library and dementia studies.

\section{References}

Alz Connected. (2017, January 20). Do we lose self control? [Blog post]. Retrieved from https://www.alzconnected.org/WorkArea/threadeddisc/print_thread.aspx?id=77\&g=posts $\& \mathrm{t}=2147531366$

Alz Connected. (2017, April 27). OCD behavior-Need advice? [Blog post]. Retrieved from https://www.alzconnected.org/discussion.aspx?g=posts\&t=2147533585 
Alzheimer Society of Canada. (2010). Rising tide: The impact of dementia on Canadian society. Retrieved from http://www.alzheimer.ca/ /media/Files/national/Advocacy /ASC_Rising\%20Tide-Executive\%20Summary_Eng.ashx

Alzheimer Society of Canada. (2012). A new way of looking at the impact of dementia. Retrieved from http://www.alzheimer.ca/ /media/Files/national/Mediareleases/asc_factsheet_new_data_09272012_en.pdf

Bates, M. J. (1999). The invisible substrate of information science. Journal of the Association for Information Science and Technology, 50(12), 1043-1050.

Campbell, D. G. Utilizing ritual in the design of information spaces for cognitively impaired. Paper presented at: Enriching Information Architecture: IA Summit; 2007 March 22; Las Vegas, Nevada.

CILIP (Chartered Institute for Library and Information Science Professionals). (2014). Sharing positive connections. CILIP Update, 13.

Cochrane, S., Knocker, S., \& Towers, H. (2014). Opening doors to people living with dementia. CILIP Update, 36-38.

Dankowski, T. (2015). Stimulating minds. American Libraries, 46(1/2), 54-57.

Dewdney, P., \& Michell, G. (1996). Oranges and peaches: Understanding communication accidents in the reference interview. Reference Quarterly, 35(4), 520-536.

Gilligan, C. (1982). In a different voice: Psychological theory and women's development. London: Harvard University Press.

Harmeyer, D. (2016). Reference chat: Filling a space in a beautiful Way. The Reference Librarian, 57(3), 254-263.

Kenner, A. M. (2008). Securing the elderly body: Dementia, surveillance, and the politics of "aging in place". Surveillance \& Society, 5(3), 252-269.

Kuhlthau, C. C. (1988). Developing a model of the library search process: Cognitive and affective aspects. $R Q, 232-242$.

Kuhlthau, C. C. (1991). Inside the search process: Information seeking from the user's perspective. Journal of the American Society for Information Science, 42(5), 361.

Kuhlthau, C. C. (1993). A principle of uncertainty for information seeking. Journal of Documentation, 49(4), 339-355.

Mellon, C. A. (1986). Library anxiety: A grounded theory and its development. College and Research Libraries, 47, 160-155.

Morton-Chang, F. M. (2015). Tipping points to institutional care for persons living with dementia: Analyzing the policy trajectory in Ontario (Doctoral dissertation, University of Toronto). 
NICE (National Institute for Health and Clinical Excellence). (2006). Guideline on supporting people with dementia and their carers in health and social care. Retrieved from https://www.nice.org.uk/guidance/cg42

RUSA (Reference and User Services Association). (2011). Guidelines for behavioral performance of reference and information services providers. Retrieved from http://www.ala.org/rusa/resources/guidelines/guidelinesbehavioral

Sevenhuijsen, S. (2003). The place of care: The relevance of the feminist ethic of care for social policy. Feminist Theory, 4(2), 179-197.

Statistics Canada. (2014, January 14). The Canadian population in 2011: Age and sex. Retrieved from http://www12.statcan.ca/census-recensement/2011/as-sa/98-311-x/98311-x2011001-eng.cfm

Statistics Canada. (2015, September 29). Canada's population estimates: Age and sex, July 1, 2015. Retrieved from http://www.statcan.gc.ca/daily-quotidien/150929/dq150929beng.htm

Tronto, J. C. (1993). Moral boundaries: A political argument for an ethic of care. London: Routledge.

United Nations. Dept. of Economic. (2002). World population ageing, 1950-2050 (No. 207). New York: United Nations.

Westbrook, L. (2015). "I'm not a social worker": An information service model for working with patrons in crisis. The Library Quarterly, 85(1), 6-25.

World Health Organization. (2015). Ageing and health. Retrived from http://www.who.int/mediacentre/factsheets/fs404/en/ 